\title{
CARACTERIZAÇÃO QUÍMICA, FÍSICO-QUÍMICA E RANCIDEZ OXIDATIVA DE MANTEIGA DE GARRAFA
}

\author{
Physical and chemical characterization and oxidative rancidity \\ of bottled butter fat
}

\author{
Maria das Graças Clemente ${ }^{1}$,Luiz Ronaldo de Abreu²
}

\begin{abstract}
RESUMO
A manteiga de garrafa é um produto largamente utilizado no Nordeste do Brasil em geral, e no norte/nordeste do Estado de Minas Gerais em particular, sendo a região de Salinas importante produtora desse tipo de manteiga. Apesar disso, não são encontrados na literatura números significativos de relatos de pesquisas sobre esse produto. Assim, este estudo foi realizado para caracterizar físico-quimicamente manteigas de garrafa produzidas na região de Salinas, norte de Minas Gerais, comparando os dados obtidos com a Legislação vigente para este produto (Brasil, 2002). O nível de umidade variou de $0,6 \%$ a 3,0\%, a gordura de $95,6 \%$ a $98,6 \%, \mathrm{o} \mathrm{pH}$ foi de 2,23 a 6,27 , a porcentagem de cloretos variou de $0,74 \%$ a $1,79 \%$, as proteínas ficaram em torno de $0,12 \%$ a $0,15 \%$, os ácidos graxos livres apresentaram de 7,60 mol/L a 48,08 mol/L e a acidez variou de 0,60\% a 9,52\% de ácido lático. Todas as manteigas de garrafa analisadas apresentaram-se fora do padrão exigido pela Legislação vigente (BRASIL, 2002).
\end{abstract}

Termos para indexação: Manteiga de garrafa, composição química, legislação.

\begin{abstract}
"Manteiga de garrafa" (bottled butter fat) is a product widely used in the Northern part of Brazil, specifically in Salinas, an important producing region in the Northern part of Minas Gerais State. In spite of that, there is no a great number of references in the literature concerning this product. This study was carried out to characterize the physical and chemical properties of this dairy product, comparing the results obtained with the current legislation for this product (BRAZIL, 2002). Moisture, fat content, $\mathrm{pH}$, salt, proteins, free fatty acids and acidity varied from 0.6 to $3.0 \%, 95.6$ to $98.6 \%, 2.23$ to $6.27,0.74$ to $1.79 \%, 0.12$ to $0.15 \%, 7.60$ to $48.08 \mathrm{~mol} / \mathrm{L}, 0.6$ to $9.52 \%$ of latic acid, respectively. All the "manteiga de garrafa" analysed, it was shown to be out of pattern considering the current legislation (BRAZIL, 2002).
\end{abstract}

Index terms: "Manteiga de garrafa" (bottled butter fat), chemical properties, legislation.

(Recebido em 8 de outubro de 2004 e aprovado em 21 de agosto de 2006)

\section{INTRODUÇÃO}

A agricultura familiar é um tipo de produção agrícola largamente utilizado na quase totalidade dos estados brasileiros, sendo particularmente importante para as regiões norte/nordeste do Estado de Minas Gerais, onde um dos produtos que se destaca para a melhoria da renda dos pequenos produtores rurais é a manteiga de garrafa.

Entende-se por manteiga de garrafa ou manteiga da terra o produto gorduroso nos estados líquido e pastoso, obtido a partir do creme de leite pela eliminação quase total da água, mediante processo tecnologicamente adequado (BRASIL, 2002).

Como a manteiga de garrafa é produzida em baixa escala por pequenos produtores, sua comercialização é realizada em barracas nas feiras livres, sendo assim, isenta de impostos, embalagens padronizadas e sistemas de comercialização sofisticados; fazendo com que poucos estudos sejam conduzidos para caracterizá-la físico-química e microbiológicamente, pois apesar de existir uma legislação específica para esse produto, essa legislação muitas vezes não é cumprida. Por isso, dada a importância da manteiga de garrafa para o norte/nordeste de Minas Gerais e seu crescimento no mercado, faz-se necessário realizar estudos no sentido de conhecer mais profundamente este produto. Face ao exposto, o presente trabalho foi desenvolvido com o objetivo de caracterizar físico-quimicamente manteigas de garrafa comercializadas em Salinas, norte de Minas Gerais, comparando os dados obtidos com os estipulados pela legislação vigente para esse produto.

\section{MATERIAL E MÉTODOS}

As amostras foram coletadas à temperatura ambiente, em feiras livres da cidade de Salinas, norte de

'Zootecnista, Mestranda - Departamento de Ciência dos Alimentos/DCA - Universidade Federal de Lavras/UFLA - Cx. P. 3037 - $37200-000$ - Lavras, MG - gra_ufla@hotmail.com

${ }^{2}$ Zootecnista, Professor Titular - Departamento de Ciência dos Alimentos/DCA - Universidade Federal de Lavras/UFLA - Cx. P. 3037 - $37200-000$ Irabreu@ufla.br 
Minas Gerais, originárias de diferentes produtores, sendo o transporte e conservação das amostras realizados sob refrigeração. As manteigas adquiridas eram embaladas em garrafas de vidro de um litro, originalmente utilizadas para cachaça.

As análises foram conduzidas no Laboratório de Laticínios do Departamento de Ciência dos Alimentos da Universidade Federal de Lavras, sendo essas: acidez titulável, determinada utilizando acidímetro Dornic, com solução de NaOH N/9 (Solução Dornic) e solução alcoólica de fenolftaleína devidamente calibrada como indicador, como descrito por Brasil (2003), sendo os resultados expressos em soluto alcalino normal; teor de gordura, determinado segundo Brasil (2003); teor de umidade, determinado em estufa a $105{ }^{\circ} \mathrm{C}-110{ }^{\circ} \mathrm{C}$, segundo Brasil (2003), teor de cloretos, determinado segundo Pereira et al. (2001); porcentagem de proteínas, determinada através do método de Kjeldahl, segundo Pereira et al. (2001); pH, determinado utilizando pHmetro portátil Tecnal TC $-2 \mathrm{P}$, previamente calibrado; teor de ácidos graxos livres e pesquisa de ranço oxidativo, determinados segundo Pereira et al. (2001).

\section{RESULTADO E DISCUSSÃO}

Os resultados obtidos nas análises realizadas com as manteigas de garrafa estão apresentados nas Tabelas 1, 2 e 3 .
Houve variação nos teores de acidez encontrados nas manteigas de garrafa analisadas, sendo que 50\% delas apresentaram valores acima do limite estabelecido pela Legislação (BRASIL, 2002), como pode ser observado na Tabela 1. As diferenças de acidez encontradas, podem ter ocorrido devido a diferenças no estado de rancificação de cada manteiga, ou a falhas durante o processamento. A falha mais comum seria a incorporação de sólidos não gordurosos, no qual está a lactose, substrato de fermentação lática.

Com relação à porcentagem de gordura, pode-se observar que todas as amostras apresentaram porcentagem de gordura abaixo do limite mínimo estabelecido pela Legislação vigente (BRASIL, 2002). Resultados semelhantes de porcentagem de gordura foram encontrados por Nassu et al. (2001), trabalhando com esse produto no Estado do Ceará, relatando índices de gordura variando de $95,4 \%$ a $99,87 \%$.

Todas as amostras analisadas apresentaram teores de umidade fora do padrão estabelecido pela Legislação (BRASIL, 2002). Resultados diferentes foram encontrados por Nassu et al. (2001), os quais variaram de 0,10 a $0,39 \%$. Essas diferenças podem ter ocorrido devido à grande variação nas etapas de fusão e cozimento da manteiga, que podem ocorrer num período que varia de 2 a 6 horas. Variação essa que ocorre dentre outros fatores, em função

Tabela 1 - Acidez, porcentagem de gordura, umidade e sólidos não gordurosos das manteigas de garrafa coletadas na região de Salinas X Legislação (BRASIL, 2002).

\begin{tabular}{ccccc}
\hline Manteigas & $\begin{array}{c}\text { Acidez } \\
\text { (soluto alcalino } \\
\text { normal) }\end{array}$ & Gordura (\%) & Umidade (\%) & $\begin{array}{c}\text { Sólidos não } \\
\text { gordurosos (g/100 g) }\end{array}$ \\
\hline Legislação & máx. 2,0 & mín. 98,5 & máx. 0,3 & máx. 1,0 \\
A & 1,17 & 98,14 & 1,00 & 0,86 \\
B & 1,21 & 98,43 & 0,60 & 0,97 \\
C & 9,13 & 97,06 & 1,00 & 1,94 \\
D & 0,99 & 97,28 & 1,19 & 0,95 \\
E & 0,60 & 96,85 & 2,20 & 1,42 \\
F & 9,52 & 97,98 & 0,60 & 1,41 \\
G & 9,52 & 97,39 & 1,20 & 1,72 \\
H & 3,09 & 96,08 & 2,20 & 1,11 \\
I & 1,18 & 97,49 & 1,40 & 1,40 \\
J & 6,75 & 95,60 & 3,00 & \\
\hline
\end{tabular}

"Fonte: Brasil (2002). 
das variações regionais, quando cada região produtora adota um método de processamento, havendo, portanto, grande variação na etapa de fusão e no tempo de cozimento. Assim, infere-se que aquelas manteigas que apresentarem maior tempo de cozimento, terão teor de umidade menor, e conseqüentemente um maior teor de gordura.

Como pode ser observado na Tabela 1 , somente $30 \%$ das amostras apresentaram porcentagem de sólidos não gordurosos de acordo com o padrão estabelecido pela Legislação (BRASIL, 2002), sendo que o restante das amostras apresentaram teores de sólidos não gordurosos acima do limite estabelecido. Observando-se a Tabela 2, verifica-se que os teores de cloretos nas amostras que estão dentro do padrão da Legislação quanto aos sólidos não gordurosos foram os menores, fazendo com que haja um menor teor de sólidos não gordurosos, o oposto ocorreu para as outras amostras.

A legislação específica para a manteiga de garrafa (BRASIL, 2002) não estipula limites para seus teores de cloretos. Os valores elevados encontrados neste trabalho, provavelmente ocorreram devido ao teor de umidade elevado nas manteigas analisadas (Tabela 1), já que o sal é na sua vasta maioria solubilizado pela água. Ambrósio et al. (2001), embora trabalhando com amostras adicionadas de cloreto de sódio durante o processamento, não detectaram a presença desses cloretos nas amostras analisadas, provavelmente, segundo os autores, devido à sua retenção no precipitado ("borra") que foi descartado das amostras. Porém, Nassu et al. (2001) encontraram valores de $0,01 \%$ a $0,12 \%$.

Os resultados apresentados na Tabela 2 permitem constatar que não houve variação nos teores de proteínas, porém não foram encontrados relatos na literatura técnico- científica e na Legislação (BRASIL, 2002) sobre porcentagem de proteínas em manteigas de garrafa, para permitir uma discussão mais comparativa.

Houve grande variação de $\mathrm{pH}$ entre as manteigas, porém também não foram encontrados relatos de $\mathrm{pH}$ de manteiga de garrafa na literatura técnico-científica, sendo que a Legislação (BRASIL, 2002) também não faz abordagens sobre esse assunto.

Da mesma forma, não foram encontrados relatos de ácidos graxos livres dessa manteiga na literatura e na Legislação (BRASIL, 2002) para fins comparativos. Os teores de ácidos graxos livres apresentaram uma grande variação, provavelmente devido a diferenças nas temperaturas de estocagem; qualidade do leite utilizado no processamento; pela ação dos microrganismos psicrotróficos, que agem produzindo lípases termorresistentes; ou pelos diferentes tempos de armazenamento.

De acordo com a Tabela 3, a maioria das manteigas apresentou resultado negativo para a pesquisa de ranço oxidativo, porém especificamente para esse tipo de manteiga, a presença de ranço oxidativo não causa nenhum dano visível. O que pode-se observar é que o ranço oxidativo nas manteigas de garrafa é imperceptível, pois mesmo as manteigas que apresentaram resultado positivo para presença de ranço oxidativo continuaram com sua aparência característica normal, e bem aceitas pelo consumidor alvo. $\mathrm{O}$ que pode ter ocorrido com as manteigas com resultado positivo é um maior tempo de armazenamento do leite, muitos deles refrigerados, e/ou maior temperatura de estocagem do produto, fazendo com que ocorresse maior ação dos microrganismos psicrotróficos na produção de lípases, as quais são termorresistentes, que ocasionam o aparecimento do ranço hidrolítico, pré-condição ao ranço oxidativo.

Tabela 2 - Porcentagem de cloretos, proteínas, pH e ácidos graxos livres das manteigas de garrafa coletadas na região de Salinas.

\begin{tabular}{ccccc}
\hline Manteigas & Cloretos $(\%)$ & Proteínas $(\%)$ & $\mathrm{pH}$ & AGL $(\%)$ \\
\hline A & 0,74 & 0,127 & 4,15 & 12,54 \\
B & 0,83 & 0,136 & 4,47 & 22,91 \\
C & 1,80 & 0,154 & 6,27 & 40,09 \\
D & 1,40 & 0,125 & 3,17 & 14,74 \\
E & 0,82 & 0,132 & 3,54 & 13,20 \\
F & 1,29 & 0,132 & 2,75 & 43,82 \\
G & 1,29 & 0,122 & 2,62 & 48,08 \\
H & 1,59 & 0,131 & 2,47 & 12,86 \\
I & 1,18 & 0,134 & 3,96 & 7,60 \\
J & 1,26 & 0,143 & 2,23 & 33,66 \\
\hline
\end{tabular}


Tabela 3 - Pesquisa de ranço oxidativo em manteigas de garrafa.

\begin{tabular}{cc}
\hline Manteigas & Ranço Oxidativo \\
\hline A & Negativo \\
B & Negativo \\
C & Positivo \\
D & Negativo \\
E & Negativo \\
F & Positivo \\
G & Positivo \\
H & Negativo \\
I & Negativo \\
J & Negativo \\
\hline
\end{tabular}

Por ser um produto fabricado artesanalmente, a manteiga de garrafa não possui suas características físico-químicas totalmente adequadas. Por isso, o que vem sendo observado é que os parâmetros estabelecidos pela Legislação (BRASIL, 2002) muitas vezes não são totalmente cumpridos, tanto pelo processo de fabricação, quanto pela matéria-prima utilizada, normalmente de baixa qualidade. A caracterização das manteigas de garrafa é importante para que haja um controle desses produtos no mercado, pois há uma grande tendência de ampliação desse mercado, inclusive para outros estados do Brasil.

\section{CONCLUSÕES}

Com base nos resultados obtidos, pode-se concluir que:

Todas as manteigas encontraram-se fora dos padrões estabelecidos pela Legislação vigente;

As análises de acidez, $\mathrm{pH}$ e ácidos graxos livres apresentaram grande variabilidade de resultados entre as amostras;
Todas as amostras apresentaram teores de gordura abaixo e umidade acima dos padrões estabelecidos pela legislação vigente;

Foi detectada a presença de ranço oxidativo em $30 \%$ das manteigas de garrafa analisadas.

\section{AGRADECIMENTO}

Agradecemos à Coordenação de Aperfeiçoamento do Pessoal de Nível Superior (CAPES), pela concessão de bolsa de estudo, importante para a condução do trabalho.

\section{REFERÊNCIAS BIBLIOGRÁFICAS}

AMBRÓSIO, C. L. B.; GUERRA, N. B.; MANCINI FILHO, J. Características de identidade, qualidade e estabilidade da manteiga de garrafa: parte 1: características de identidade e qualidade 1. Revista da Sociedade Brasileira de Ciência e Tecnologia de Alimentos, Campinas, v. 21, n. 3, p. 314-320, dez. 2001

BRASIL. Ministério da Agricultura, Pecuária e Abastecimento. Instrução normativa DAS n. 22, de 14 de abril de 2003. Métodos analíticos oficiais físico-químicos para controle de leite e produtos lácteos. Brasília, DF, 14 abr. 2003.

BRASIL. Ministério da Saúde. Ministério da Agricultura, Pecuária e Abastecimento e da Secretaria de Vigilância Sanitária. Nova legislação comentada de produtos lácteos. Brasília, DF, 2002. 327 p.

NASSU, R. T.; ARAÚJO, R. S.; BORGES, M. F.; LIMA, J. R.; MACEDO, B. A.; LIMA, M. H. P.; BASTOS, M. S. R. Diagnóstico das condições de processamento de produtos regionais derivados do leite no Estado do Ceará. Fortaleza: Embrapa Agroindústria Tropical, 2001. 28 p.

PEREIRA, D. B.; SILVA, P. H. F.; COSTA JÚNIOR, L. C. G.; OLIVEIRA, L. L. Físico-química do leite e derivados: métodos analíticos. 2. ed. Juiz de Fora: Epamig, 2001. 234 p. 